\title{
MITRAL ANNULAR SIZE AND SHAPE IN SHEEP WITH ANNULOPLASTY RINGS
}

Julie R. Glasson, MDa

G. Randall Green, $\mathrm{MD}^{\mathrm{a}}$

J. Francisco Nistal, MD

Paul Dagum, MDa

Masashi Komeda, $\mathrm{MD}, \mathrm{PhD}^{\mathrm{a}}$

George T. Daughters, MS ${ }^{a, b}$

Ann F. Bolger, $\mathrm{MD}^{\mathrm{c}, \mathrm{d}}$

Linda E. Foppiano, MD

Neil B. Ingels, Jr, $\mathrm{PhD}^{\mathrm{a}, \mathrm{b}}$

D. Craig Miller, $\mathrm{MD}^{\mathrm{a}, \mathrm{f}}$
Background: Mitral annuloplasty is an important element of most mitral repairs, yet the effects of various types of annuloplasty rings on mitral annular dynamics are still debated. Recent studies suggest that flexible rings preserve physiologic mitral annular area change during the cardiac cycle, while rigid rings do not. Methods: To clarify the effects of mitral ring annuloplasty on mitral annular dynamic geometry, we sutured 8 radiopaque markers equidistantly around the mitral anulus in 3 groups of sheep ( $n=7$ each: no ring, Carpentier-Edwards semi-rigid Physio-Ring [Baxter Healthcare Corp, Edwards Division, Santa Ana, Calif], and Duran flexible ring [Medtronic, Inc, Minneapolis, Minn]). Ring sizes were selected according to anterior leaflet area and inter-trigonal distance (Physio-Ring $28 \mathrm{~mm}, \mathrm{n}=7$; Duran ring $31 \mathrm{~mm}, \mathrm{n}=5$, and $29 \mathrm{~mm}, \mathrm{n}=2$ ). After $8 \pm 1$ days of recovery, the sheep were sedated and studied by means of biplane videofluoroscopy. Mitral annular area was calculated from 3-dimensional marker coordinates without assuming circular or planar geometry. Results: In the no ring group, mitral annular area varied during the cardiac cycle by $11 \% \pm 2 \%$ (mean \pm SEM; maximum $=7.6 \pm 0.2$, minimum $\left.=6.8 \pm 0.2 \mathrm{~cm}^{2} ; P \leq .001\right)$. Mitral annular area was fixed in the Physio-Ring group $\left(4.6 \pm 0.1 \mathrm{~cm}^{2}\right)$ and, surprisingly, also static in the Duran ring group $\left(4.8 \pm 0.1 \mathrm{~cm}^{2} ; P=.26 \mathrm{vs}\right.$ Physio-Ring). Furthermore, mitral annular 3-dimensional shape changed in the no-ring group during the cardiac cycle, but not in the Physio-Ring or Duran groups. Conclusions: Mitral annular area and shape did not change during the cardiac cycle after ring annuloplasty, regardless of ring type. Thus mitral annular area reduction, independent of intrinsic ring flexibility, is the chief mechanism responsible for the salutary effects of mitral ring annuloplasty. ( $J$ Thorac Cardiovasc Surg 1999;117:302-9)
$\mathrm{M}$ itral valve reconstruction is a well-established surgical procedure for patients with many forms of mitral regurgitation. An important component of mitral repair is annular narrowing and reinforcement with an annuloplasty ring. The complete (in contrast to partial) rings fall into two basic families: rigid (originally devel-

From the Department of Cardiovascular and Thoracic Surgery, ${ }^{\mathrm{a}}$ the Division of Cardiovascular Medicine, ${ }^{c}$ and the Department of Anesthesia, ${ }^{\text {e }}$ Stanford University School of Medicine, Stanford, Calif, Cardiac Surgery ${ }^{\mathrm{f}}$ and Cardiology Sections, ${ }^{\mathrm{d}}$ Department of Veterans Affairs Medical Center, Palo Alto, Calif, and the Department of Cardiovascular Physiology and Biophysics, ${ }^{\mathrm{b}}$ Research Institute of the Palo Alto Medical Foundation, Palo Alto, Calif.

Presented in part at the American Heart Association Seventieth Scientific Sessions, Orlando, Fla, Nov 9-12, 1997.

Supported by grants HL-29589 and HL-48837 from the National Heart, Lung and Blood Institute and the Veterans Administration Medical Research Service. Drs Glasson, Green, Dagum, and oped by Carpentier ${ }^{1}$ ) and flexible (as designed by Duran and $\mathrm{Umbago}^{2}$ ). Both types of rings reduce mitral annular size, but the Duran ring (Medtronic, Inc, Minneapolis, Minn) is completely flexible and theoretically can change its size and shape during the cardiac cycle. Because of the purported added benefits of ring

Komeda are Carl and Leah McConnell Cardiovascular Surgical Research Fellows. Dr Glasson is also a Katharine McCormick Scholar and recipient of The Thoracic Surgery Foundation Research Fellowship Award.

Received for publication Jan 23, 1998; revisions requested April 2, 1998; revisions received July 27, 1998; accepted for publication Sept 29, 1998.

Address for reprints: D. Craig Miller, MD, Department of Cardiovascular and Thoracic Surgery, Falk Cardiovascular Research Center, Stanford University School of Medicine, Stanford, CA 94305-5247.

$12 / 1 / 94821$ 


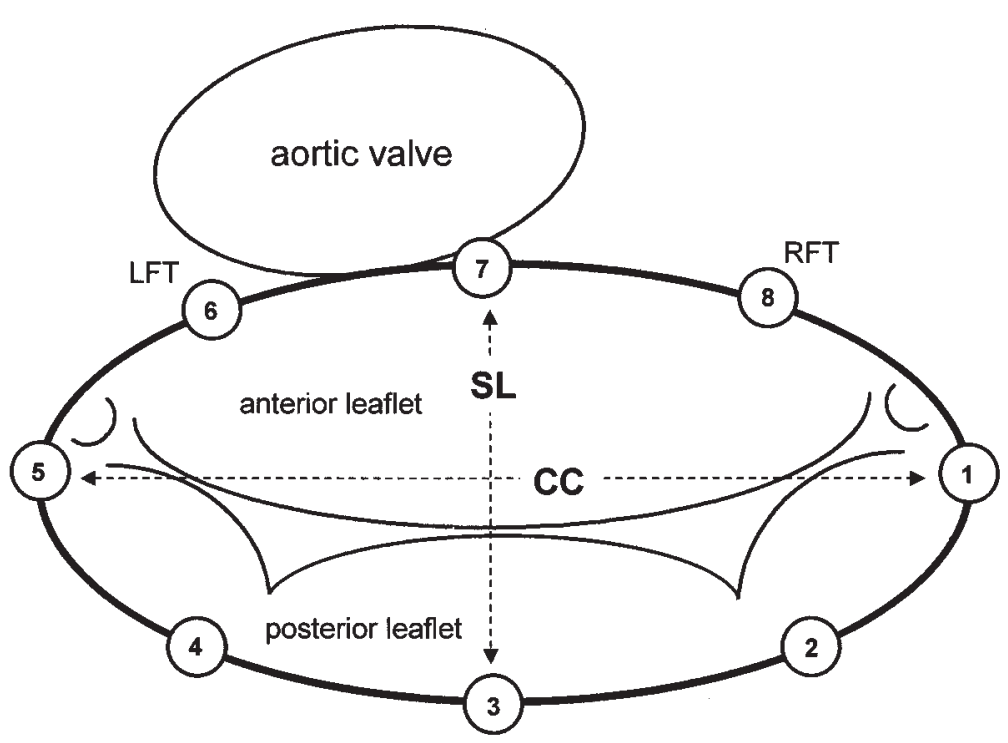

Fig 1. Schematic representation of the mitral annular marker array (marker numbers are indicated inside the circles). The septal-lateral ( $S L$, between markers 3 and 7) and commissure-commissure (CC, between markers 1 and 5) dimensions are illustrated. The 6 contiguous segments between the fibrous trigones (markers 6 and 8 ) centered on the posterior anulus represented the muscular region of the anulus. LFT and RFT, Left and right fibrous trigones, respectively.

flexibility, Carpentier recently introduced the Carpentier-Edwards (CE) semi-rigid Physio-Ring (Baxter Healthcare Corp, Edwards Division, Santa Ana, Calif). ${ }^{3}$ The CE Physio-Ring is selectively rigid in the anterior portion and somewhat flexible and more deformable in the posterior part.

The functional importance of annuloplasty ring flexibility, however, remains unclear. Experimental data from our laboratory in normal sheep suggest that preservation of the natural dynamic changes in mitral annular size and shape during the cardiac cycle would be the most physiologic approach, ${ }^{4}$ implying that flexible annuloplasty rings may be beneficial in terms of preservation of natural mitral annular dynamic motion. Recent clinical investigations from Japan have suggested that mitral annular configuration and dynamics are more physiologic in patients with a flexible Duran ring than in those who received a rigid Carpentier ring. ${ }^{5-7}$ Mitral annular area in these studies, however, was estimated from planimetric measurements of 2-dimensional (2D) circumferential annular projections reconstructed from echocardiographic long-axis image planes, without the benefit of measuring discrete or consistent mitral annular sites or three-dimensional (3D) data.

To investigate the putative benefit of maintaining "physiologic" annular flexibility after annuloplasty in terms of annular 3D dynamics, we used the myocardial marker technology ${ }^{8}$ in a conscious, closed-chest ovine preparation to analyze and compare continuous 3D mitral annular motion in 3 groups of animals: normal sheep without an annuloplasty ring (group N), animals with a flexible Duran ring (group D), and those with the semi-rigid CE Physio-Ring (group P).

\section{Methods}

Surgical preparation. Twenty-one healthy adult castrated male sheep ${ }^{4}$ of similar size $(67 \pm 8 \mathrm{~kg}$ [mean \pm SD] $)$ had miniature tantalum radiopaque helices inserted into the left ventricular (LV) free wall and septum, as described previously. ${ }^{9}$

During cardiopulmonary bypass with the heart arrested, 8 miniature tantalum radiopaque markers were sutured equidistantly around the circumference of the mitral anulus, 1 near each commissural area (markers 1 and 5) and 3 along the perimeters of the anterior (markers 6-8) and posterior (markers 2-4) leaflets, as shown in Fig 1. The animals were then randomized to 1 of 3 groups: no ring, group N; Physio-Ring, group P; or Duran ring, group D. Ring sizes were selected according to the size of the anterior leaflet and the intertrigonal distance using clinically accepted standard methods. In group P, all 7 animals received a $28 \mathrm{~mm}$ Physio-Ring; in group D, 5 animals received a $31 \mathrm{~mm}$ Duran ring, and 2 received a $29 \mathrm{~mm}$ Duran ring. A micromanometer pressure transducer (P4.5-X6, Konigsberg Instruments, Inc, Pasadena, Calif) was placed in the LV chamber via the apex. After marker and ring placement, mitral valve competence was demonstrated in all 
animals by infusing saline solution into the ventricle and by epicardial color Doppler echocardiography.

Experimental protocol. After $8 \pm 1$ (mean \pm 1 SD) days, each animal was taken to the experimental animal cardiac catheterization laboratory for hemodynamic and videofluorographic data acquisition. Details of the techniques used have been previously reported. ${ }^{4}$ UL-FS49 (Boehringer-Ingelheim, Ridgefield, Conn), a highly specific negative chronotropic agent that does not change the QT interval, inotropic state, or systolic or diastolic blood pressure, ${ }^{10}$ was administered $(8 \mathrm{mg}$ intravenously) to reduce heart rate (which facilitated subsequent cinefluoroscopic visualization and tracking of marker motion). To minimize reflex sympathetic and parasympathetic responses that occur in conscious animals, autonomic blockade was accomplished with a low-dose intravenous infusion of esmolol $(20-50 \mu \mathrm{g} / \mathrm{kg}$ per minute, titrated to reduce heart rate below $\left.110 \mathrm{~min}^{-1}\right)$ and atropine sulfate $(0.01$ $\mathrm{mg} / \mathrm{kg}$ intravenously).

For all data acquisition runs, the hearts were in normal sinus rhythm and ventilation was arrested briefly at end-expiration. All hemodynamic and biplane videofluoroscopic data recordings were obtained during steady-state conditions and over a physiologic range of peak LV systolic pressures induced by vena caval occlusion. Data sequences containing premature ventricular contractions were discarded and subsequently repeated.

All animals received humane care in compliance with the "Principles of Laboratory Animal Care" formulated by the National Society for Medical Research and the "Guide for Care and Use of Laboratory Animals" prepared by the National Academy of Sciences and published by the National Institutes of Health (DHEW [NIH] Publication 85-23, revised 1985). This study was approved by the Stanford Medical Center Laboratory Research Animal Review Committee and conducted according to Stanford University policy.

Data acquisition. Images were acquired with the animal in the right lateral decubitus position with a Philips Optimus 2000 biplane lateral ARC 2/Poly DIAGNOST C2 system (Philips Medical Systems, North America Company, Pleasanton, Calif) with the image intensifiers in 9-inch fluoroscopic mode. Data from the $2 \mathrm{x}$-ray views were digitized and processed to yield the 3D coordinates of each marker every $16.7 \mathrm{~ms}$. Specific details of the data acquisition and analysis steps have been described previously. ${ }^{9}$ Using myocardial markers for the 3D assessment of cardiac dynamics has some minor limitations; this technique allows accurate and reproducible determination of marker position with a mean overall error of only $0.1 \pm 0.6 \mathrm{~mm} .{ }^{11}$ All annular markers were sutured in similar locations regardless of whether a ring was placed or not.

Data analysis. Data from 2 consecutive steady-state beats for all animals were averaged and analyzed.

Hemodynamics. For each cardiac cycle, the time of enddiastole was defined as the videofluoroscopic frame containing the beginning of positive deflection of the electrocardiographic (ECG) voltage ( $\mathrm{R}$ wave), and end-systole was defined as the videofluoroscopic frame immediately (16.7 $\mathrm{ms}$ ) before the time of peak negative $\mathrm{LV} \mathrm{dP} / \mathrm{dt}$.
Systolic LV function. Instantaneous LV volume was calculated with a multiple elliptical cylindrical/cone model as described previously. ${ }^{9} \mathrm{LV}$ end-systolic pressure $\left(\mathrm{P}_{\mathrm{es}}\right)$ and volume $\left(\mathrm{V}_{\mathrm{es}}\right)$ during preload reduction were analyzed with the use of an iterative computer algorithm to define the end-systolic pressure volume relationship to assess global LV systolic performance. ${ }^{12}$ Least-squares linear regression was used to fit a line of the form

$$
\mathrm{P}_{\mathrm{es}}=\mathrm{E}_{\mathrm{es}}\left(\mathrm{V}_{\mathrm{es}}-\mathrm{V}_{0}\right)
$$

to these end-systolic points, where $\mathrm{E}_{\mathrm{es}}$ and $\mathrm{V}_{0}$ are the slope and volume axis intercept of the end-systolic pressure volume relationship, respectively.

Mitral annular geometry. Mitral annular area, perimeters, and dimensions were computed from the 3D marker coordinates, without assuming circular or planar geometry. To compute mitral annular area, the center of mass of all 8 annular markers was determined as the mitral annular centroid. The 8 mitral annular markers and centroid were then used to divide the mitral anulus into 8 triangular "pie-pieces" whose individual areas were added together to compute overall mitral annular area. Mitral annular area was also calculated as the sum of 6 triangular areas derived from all possible triplets of annular marker coordinates to determine whether method of area calculation would alter the area calculations. Because this latter calculation correlated well with the former calculation using the mitral annular centroid $(r=0.97$ [group N], 0.97 [group P], and 0.83 [group D]), only areas calculated with the use of the mitral annular centroid are presented in this report. The mitral annular muscular region length was calculated as the sum of the 6 contiguous mitral annular segment (mostly posterior) lengths between annular markers 8 and 6 (Fig 1). The septal-lateral mitral annular dimension was calculated as the linear distance in 3D space between annular markers 3 and 7 (middle of the anterior mitral anulus to a corresponding point on the posterior anulus), and the commissure-commissure mitral annular dimension was computed as the linear distance in 3D space between annular markers 1 and 5 (Fig 1).

The shape of the entire mitral valve and subvalvular apparatus was also analyzed with the use of a $3 \mathrm{D}$ coordinate system defined with the origin at the midpoint of the commissural markers (markers 1 and 5) with the negative $\mathrm{z}$-axis directed through the LV apical marker (ie, along the LV long axis). This reference system allowed description of the distance above or below the annular origin of any marker in 3D coordinates; positive $\mathrm{z}$-coordinates were toward the atrium and negative $\mathrm{z}$-coordinates were closer to the LV apex. To quantitate further the mitral annular shape changes occurring during the cardiac cycle, the z-coordinates of each mitral annular marker at end-diastole were compared with those at end-systole to determine whether ring annuloplasty altered the presence and behavior of the previously described mitral annular "saddlehorn" configuration. 4,9

Statistical analysis. All data are reported as mean \pm 1 standard error of the mean $( \pm 1$ SEM) unless otherwise stated. Hemodynamic and marker-derived data from 2 consecutive steady-state beats in all 7 hearts for each group were time- 
Table I. Hemodynamics

\begin{tabular}{lcccc}
\hline Group & $H R\left(\mathrm{~min}^{-1}\right)$ & $L V E D P(\mathrm{~mm} \mathrm{Hg})$ & $E F(\%)$ & $S W(\mathrm{~mm} \mathrm{Hg} \bullet \mathrm{mL})$ \\
\hline No ring & $99 \pm 12^{*}$ & $16 \pm 3^{*}$ & $18 \pm 2 *$ & $3053 \pm 1149 *$ \\
Physio-Ring & $100 \pm 8$ & $19 \pm 6$ & $19 \pm 4$ & $3.3 \pm 0.4^{*}$ \\
Duran ring & $102 \pm 6$ & $20 \pm 6$ & $18 \pm 4$ & $2467 \pm 807$ \\
\hline
\end{tabular}

Data are expressed as mean $\pm \mathrm{SD} ; \mathrm{n}=7$ sheep for each group. $H R$, Heart rate; $L V E D P$, left ventricular end-diastolic pressure; $E F$, left ventricular ejection fraction; $S W$, left ventricular stroke work; Ees, left ventricular end-systolic elastance. Note that LV volume was computed from the epicardial LV markers without taking into consideration LV muscle mass; hence LV volume is overestimated, and the contribution of systolic LV wall thickening to chamber emptying is ignored. This makes the ejection fraction calculations underestimates of the true values; as a corollary, the stroke work figures are overestimates.

$* P=$ NS by analysis of variance for all 3 groups.

aligned at the upstroke of the R wave of the ECG (end-diastole). The mean and SEM for each variable were computed for the 14 beats in each group at end-diastole and at 16 time samples (267 ms) before and after end-diastole, such that a curve could be generated depicting the behavior of any variable throughout 1 cardiac cycle (approximately $534 \mathrm{~ms}$ in this experiment). Comparison of hemodynamic and geometric variables between groups was performed by means of repeated-measures analysis of variance; when indicated by a significant $\mathrm{F}$ statistic $(P \leq .05)$, specific differences were isolated using the Bonferroni correction for multiple comparisons. Mitral annular dimensions at specified time points in the cardiac cycle were also compared within each group using the Student $t$ test for paired observations.

\section{Results}

Postmortem examination of excised hearts revealed all LV epicardial markers to be within $1 \mathrm{~mm}$ of the epicardial surface and all 8 annular markers to be within 1 $\mathrm{mm}$ of the mitral anulus (as defined by the junction of the leaflet and left atrial endocardium). Additionally, all annuloplasty rings were well seated without dehiscence at the time of necropsy.

Hemodynamics. Data were obtained for all 3 groups. No mitral regurgitation was present in any animal, as evidenced by transthoracic color Doppler echocardiography at the time of data acquisition. Average heart rate for all sheep did not differ between groups, with an overall mean of $101 \pm 8 \mathrm{~min}^{-1}$ (mean \pm $1 \mathrm{SD})$. End-diastolic LV pressure, LV ejection fraction, LV stroke work, and LV $\mathrm{E}_{\mathrm{es}}$ were not statistically different between groups (Table I), indicating that all animals had similar global LV systolic function despite the presence or type of annuloplasty ring.

Mitral annular size and shape. Fig 2 shows the changes in mitral annular area versus time for all animals in each group. Note that in group $\mathrm{N}$ (no ring), the mitral annular area changed dynamically during the cardiac cycle (overall change $=11 \% \pm 2 \%$ ) from a maximum of $7.6 \pm 0.2 \mathrm{~cm}^{2}$ in mid-diastole to a minimum of $6.8 \pm 0.2 \mathrm{~cm}^{2}(P \leq .001)$ in very early systole. As expected, mitral annular area did not change during the cardiac cycle in the Physio-Ring group (fixed at $4.6 \pm 0.1 \mathrm{~cm}^{2}$ ). Surprisingly, mitral annular area did not change during the cardiac cycle in the Duran ring group either, also being fixed at the same size as that in the Physio-Ring group $\left(4.8 \pm 0.1 \mathrm{~cm}^{2}\right.$ vs $\left.4.6 \pm 0.1 \mathrm{~cm}^{2}, P=.26\right)$.

Corresponding similarities were noted in the length of the posterior (or muscular) mitral annular region during the cardiac cycle. As shown in Fig 3, the maximal length of the muscular mitral anulus in group $\mathrm{N}$ (no ring) was $7.7 \pm 0.2 \mathrm{~cm}$. After presystolic contraction, the length of the muscular mitral annular region shortened to a minimum value of $7.2 \pm 0.2 \mathrm{~cm}(P \leq$ $.001)$, as previously reported. ${ }^{4}$ No such changes were noted in the muscular mitral annular region in either the Physio-Ring group (fixed at $5.7 \pm 0.1 \mathrm{~cm}$ ) or the Duran ring group (also fixed at $5.7 \pm 0.1 \mathrm{~cm}, P=.52$ vs Physio-Ring group).

Mitral annular septal-lateral and commissure-commissure dimensions were calculated to determine and compare one descriptor of mitral annular shape. These parameters varied dynamically during the cardiac cycle in group $\mathrm{N}$ (no ring), but did not change in either ring group (Fig 4). The septal-lateral and commissure-commissure dimensions in group $\mathrm{N}$ were maximal in middiastole (septal-lateral $27.1 \pm 0.3 \mathrm{~mm}$, commissurecommissure $36.7 \pm 0.8 \mathrm{~mm})$. The septal-lateral dimension decreased during presystole to a minimum of $25.3 \pm 0.3 \mathrm{~mm}(P \leq .001$ vs maximum), and the commissure-commissure dimension decreased during both presystole and systole to a minimum of $33.9 \pm 0.5 \mathrm{~mm}$ ( $P \leq .001$ vs maximum), as described previously. ${ }^{4}$ On the other hand, the septal-lateral and commissure-commissure dimensions did not change during the cardiac cycle in either ring group. The septal-lateral dimension was static at $21.6 \pm 0.6 \mathrm{~mm}$ in the Physio-Ring group and at $21.8 \pm 0.4 \mathrm{~mm}$ in the Duran ring group $(P=.32$ vs Physio-Ring). The commissure-commissure measurement was static at $27.9 \pm 0.7 \mathrm{~mm}$ in the PhysioRing group and at $27.7 \pm 0.5$ in the Duran ring group ( $P=.42$ vs Physio-Ring).

In terms of mitral annular 3D shape as measured by z-coordinates, all groups demonstrated a small mitral annular elevation toward the aortic valve (or "saddle- 


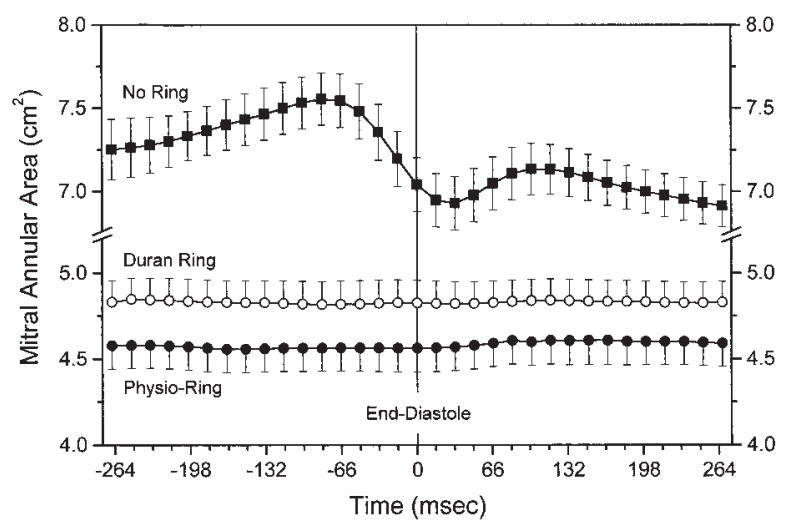

Fig 2. Depiction of mitral annular area $\left(\mathrm{cm}^{2}\right)$ versus time for animals with no ring (solid squares), Duran ring (open circles), and Physio-Ring (solid circles). Data are mean values for all animals in each group, with error bars representing \pm 1 SEM. The graph depicts 1 average cardiac cycle length extending from beginning diastole to end-systole, with temporal data aligned at the upstroke of the ECG R wave (enddiastole, defined by the vertical line at $\mathrm{t}=0$ ).

horn") in the anterior mitral annular region between markers 6 and 7. More important, in both ring groups the mitral annular "saddlehorn" moved in the same manner as that in the no ring group (group N), that is, the mitral annular "saddlehorn" moved cephalad and the posterior mitral anulus moved caudad from enddiastole to end-systole, regardless of the type of annuloplasty ring present (Fig 5).

\section{Discussion}

The dynamic flexibility of the mitral anulus has been well established in multiple experimental animal preparations, ${ }^{4,9,13,14}$ as well as in human studies. ${ }^{15-19}$ Yet the clinical importance of maintaining normal physiologic mitral annular dynamics and motion after mitral valve repair coupled with an annuloplasty ring remains an unresolved issue. Consequently, the choice of what type of ring to use, flexible versus rigid or complete versus partial, is based largely on empiric knowledge and personal preference, because the true impact of various types of rings on mitral annular dynamics and LV systolic function continues to be debated. Traditionally, mitral annuloplasty with a flexible prosthetic ring has been assumed to preserve normal mitral annular flexibility, thereby allowing a more physiologic repair. ${ }^{2,5-7}$ However, our findings in this experimental investigation of mitral annular size and shape in sheep with annuloplasty rings suggest otherwise.

The experimental model in this report used a system

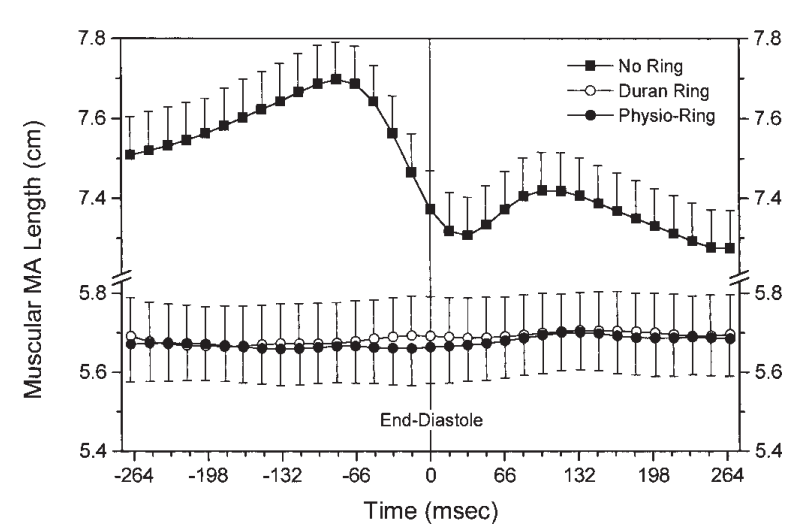

Fig 3. Illustration of the length of the mitral annular (MA) muscular region $(\mathrm{cm})$ versus time for animals with no ring (solid squares), a Duran ring (open circles), and a PhysioRing (solid circles). The data indicate mean values for all animals in each group with the error bars representing \pm 1 SEM. The graph depicts 1 average cardiac cycle extending from beginning diastole to end-systole, with data aligned at the upstroke of the ECG R wave (end-diastole, defined by the vertical line at $\mathrm{t}=0$ ).

that allowed accurate beat-by-beat calculation of mitral annular area and shape in true 3D space, independent of any floating internal reference system, for example, those used for echocardiographic or angiographic measurements. It is important to note that this method of data acquisition may explain the differences between our current observations and the findings reported previously by Okada and Yamaura and their colleagues. ${ }^{5-7}$

All animals studied were healthy adult sheep, and none had evidence of hemodynamically significant mitral regurgitation by transthoracic Doppler echocardiography at the time of data collection. All data were obtained with the animals in normal sinus rhythm, with equivalent amounts of autonomic blockade in all groups. Hemodynamics and LV systolic mechanics, including heart rate, LV end-diastolic pressure, LV ejection fraction, LV stroke work, and LV elastance, were not significantly different between groups, indicating similar global LV function. Thus any observed differences in mitral annular dynamics between the groups cannot be explained on the basis of differences in LV systolic performance.

In group $\mathrm{N}$ (the no ring group), mitral annular area decreased during the cardiac cycle as reported previously. ${ }^{4}$ This area reduction was absent in the PhysioRing group, as expected; although the Physio-Ring is called a "semi-rigid" ring, its more flexible posterior elements are constructed of Elgiloy bands separated by polyester film strips, making it relatively rigid com- 


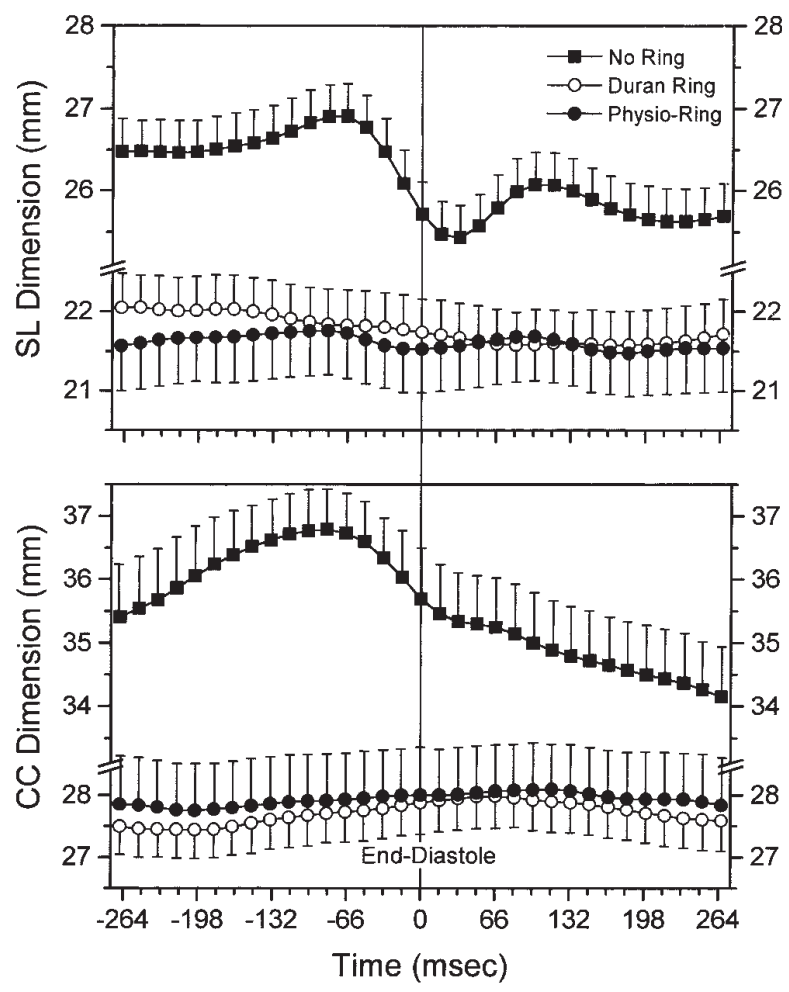

Fig 4. Graph of the mitral septal-lateral (SL, mm) and commissure-commissure $(C C, \mathrm{~mm})$ dimensions versus time for animals with no ring (solid squares), a Duran ring (open circles), and a Physio-Ring (solid circles). Data are mean values for all animals in each group, with the error bars representing \pm 1 SEM. Each graph depicts 1 average cardiac cycle extending from beginning diastole to end-systole, with the data with respect to time aligned at the upstroke of the ECG $\mathrm{R}$ wave (end-diastole, defined by the vertical line at $\mathrm{t}=0$ ).

pared to the totally flexible Duran ring. Consequently, the lack of changes in annular size and shape noted in the Physio-Ring group were not surprising. On the other hand, the total flexibility of the Duran ring has been thought to be advantageous because it could theoretically change its size and shape during the cardiac cycle as would the natural anulus. Surprisingly, the results from this study do not confirm this concept. In the Duran ring group, there was also no change in annular area during the cardiac cycle. Moreover, both ring groups showed absence of posterior (or muscular) annular shortening, as well as the physiologic mitral annular shape change detected by the septal-lateral and commissure-commissure annular dimensions. Thus these observations indicate that ring annuloplasty, whether totally flexible or semi-rigid, freezes the anulus in a fixed size and shape; neither ring preserved mitral annular natural flexibility.

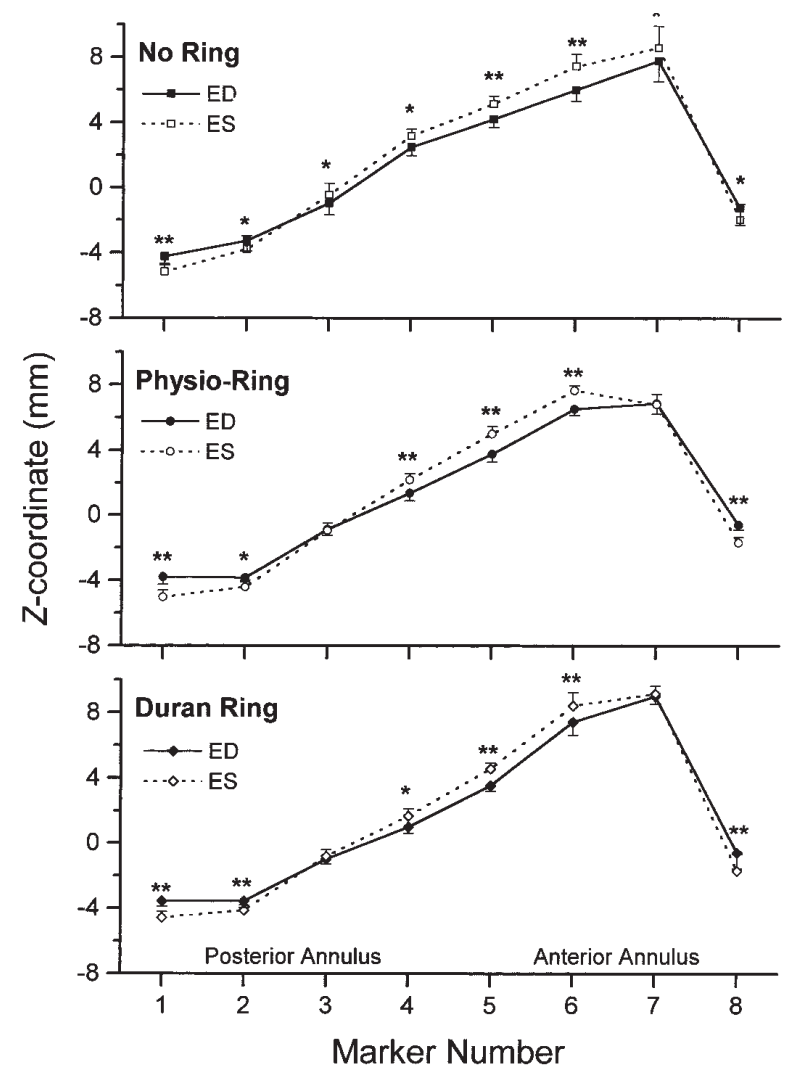

Fig 5. Mitral annular marker positions with respect to the LV long axis (z-coordinates) at end-diastole (ED, solid) and at end-systole ( $E S$, dashed line) for animals with no ring (top panel), a semi-rigid Physio-Ring (middle panel), and a flexible Duran ring (bottom panel). Data are mean marker positions ( $\mathrm{mm}$ ) for each group; the error bars represent \pm 1 SEM. $* P \leq .5, * * P \leq .005 z$-coordinate at end-diastole versus endsystole for each group. Note that an increase in the height of the anterior annular "saddlehorn" during systole was present in all animals, regardless of the presence or type of annuloplasty ring.

The previously described anterior annular "saddlehorn" shape, albeit a subtle one, was maintained in both ring groups. More important, the increase in height of this anterior mitral annular "saddlehorn" during LV systole was sustained to an equivalent extent in both ring groups. This systolic excursion may be important in minimizing LV outflow tract impedance during ejection, ${ }^{9}$ which others have suggested could be impeded by rigidity of the anterior mitral anulus. ${ }^{14,20}$ These current data do not support this speculation, because the normal upward displacement of the anterior anulus was not altered by the presence of either type of ring.

It is important to note that fixation of the anulus with either type of ring reduced its size significantly, which 
is one of the clinical goals when an annuloplasty ring is being used. The minimum mitral area observed at any time during the cardiac cycle in group $\mathrm{N}$ (no ring) was nearly $50 \%$ larger than the fixed annular area in sheep with either type of ring. Additionally, this annular area reduction was nearly equivalent between ring groups, indicating that sizing techniques used for both types of rings were comparable. This substantial annular size reduction after annuloplasty may actually explain the lack of area and shape change during the cardiac cycle we observed in the ring groups. Most mitral annular size reduction in sheep actually occurs before ventricular contraction $^{4}$ when the anulus physiologically becomes smaller during atrial systole. Consequently, any additional reduction in mitral annular size, once it is fixed and smaller than the physiologic minimum, would likely require a force far greater than that generated by ventricular contraction. Furthermore, because of the lengthtension relationship of cardiac muscle, the shorter muscle fiber lengths in a smaller anulus means that it is likely to generate less annular force. Finally, the lack of differences in mitral annular dynamics seen between the 2 ring groups could also possibly be attributed to the sutures used to implant the rings. The interrupted horizontal mattress sutures placed closely together around the entire circumference of the ring must be associated with some degree of "rigidizing" effect on the mitral anulus.

This study of both flexible and semi-rigid annuloplasty rings showed identical effects on mitral annular dynamics, that is, abolishment of annular flexibility independent of ring type. As such, maintenance of annular flexibility probably does not have any major clinical importance in the overall salutary effects of ring annuloplasty. Recent studies from our laboratory have shown that early systolic incomplete mitral leaflet closure resulting from acute posterolateral wall LV ischemia is associated primarily with annular enlargement without changes in LV geometry, leaflet prolapse, or apical displacement of any part of the mitral apparatus. ${ }^{21}$ As such, annuloplasty should be useful in the treatment of patients with ischemic mitral regurgitation: Reducing the size of the anulus brings the leaflet edges closer together, thereby allowing more coaptation to occur. Data from the current experiment support this concept; furthermore, these observations indicate that mitral annular size reduction, independent of maintenance of annular flexibility, is the primary corrective mechanism. Ongoing studies in our laboratory have been designed to answer the question of whether or not annular area reduction alone (regardless of type of ring used) is sufficient to prevent the development of ischemic mitral regurgitation.
Limitations. The use of myocardial markers for 3D assessment of cardiac dynamics has some minor inherent limitations. This technology allows accurate and reproducible determination of marker position, with a mean overall error of only $0.1 \pm 0.6 \mathrm{~mm}$ every 16.7 ms. ${ }^{11}$ Additionally, marker technology allows tracking of discrete sites on the mitral apparatus in 3D space with respect to a fixed external laboratory coordinate system. Such a fixed external coordinate system is not possible with sonomicrometry, which usually is based on an internal reference system. Marker technology does require suturing of small tantalum coil markers to the area of interest, in this case the mitral anulus. The possibility of annular markers interfering with normal mitral annular motion should be minimal, however, because the markers are very small, weighing less than $20 \mathrm{mg}$ each. The small size of the tantalum coils is another advantage over sonomicrometry, which uses larger and heavier crystals requiring wire attachments.

The main limitation in this study is the use of an animal model. Because the fiber architecture of the ovine mitral anulus may not be identical to that of human beings, these results may possibly not be directly applicable to man, especially patients with impaired LV systolic function. One would expect less dynamic annular motion if depressed LV systolic performance is present; thus a similar experiment in impaired hearts might show less pronounced differences between the no-ring and the ring groups. Further studies of mitral annular motion, leaflet dynamics, and mitral regurgitation during myocardial ischemia are currently underway in our laboratory to determine the effects of ring annuloplasty on overall mitral apparatus function in the setting of a clinically relevant ischemic insult.

\section{REFERENCES}

1. Carpentier AF. La valvuloplastie reconstitutive. Une nouvelle technique de valvuloplastie mitrale. Presse Med 1969;77:251-3.

2. Duran CMG, Umbago JL. Clinical and hemodynamic performance of a totally flexible prosthetic ring for atrioventricular valve reconstruction. Ann Thorac Surg 1976;22:458-63.

3. Carpentier AF, Lessana A, Relland JYM, Belli E, Mihaileanu S, Berrebi AJ, et al. The "Physio-Ring": an advanced concept in mitral valve annuloplasty. Ann Thorac Surg 1995;60:1177-86.

4. Glasson JR, Komeda M, Daughters GT, Foppiano LE, Bolger AF, Tye TL, et al. Most ovine mitral annular three-dimensional size reduction occurs before ventricular systole and is abolished with ventricular pacing. Circulation 1997;96:(Suppl):II115-23.

5. Okada Y, Shomura T, Yamaura Y, Yoshikawa J. Comparison of the Carpentier and Duran prosthetic rings used in mitral reconstruction. Ann Thorac Surg 1995;59:658-63.

6. Yamaura Y, Yoshikawa J, Yoshida K, Hozumi T, Akasaka T, Okada Y. Three-dimensional analysis of configuration and dynamics in patients with an annuloplasty ring by multiplane 
transesophageal echocardiography: comparison between flexible and rigid annuloplasty rings. J Heart Valve Dis 1995;4:618-622.

7. Yamaura Y, Yoshida K, Hozumi T, Akasaka T, Okada Y, Yoshikawa J. Three-dimensional echocardiographic evaluation of configuration and dynamics of the mitral annulus in patients fitted with an annuloplasty ring. J Heart Valve Dis 1997;6:43-47.

8. Ingels NB, Daughters GT, Stinson EB, Alderman EL. Measurement of midwall myocardial dynamics in intact man by radiography of surgically implanted markers. Circulation 1975;52:859-67.

9. Glasson JR, Komeda M, Daughters GT, Niczyporuk MA, Bolger $\mathrm{AF}$, Ingels NB, et al. Three-dimensional regional dynamics of the normal mitral anulus during left ventricular ejection. J Thorac Cardiovasc Surg 1996;111:574-85.

10. Schipke JD, Harasawa Y, Sugiura S, Alexander J, Burkhoff D. Effect of a bradycardic agent on the isolated blood-perfused canine heart. Cardiovasc Drugs Ther 1991;5:481-8.

11. Daughters GT, Sanders WJ, Miller DC, Schwarzkopf A, Mead $\mathrm{CW}$, Ingels NB. A comparison of two analytical systems for three-dimensional reconstruction from biplane videoradiograms. IEEE Comput Soc Press 1989;15:79-82.

12. Kono A, Maughan WL, Sunagawa K, Hamilton K, Sugawa K, Weisfeldt ML. The use of left ventricular end-ejection pressure and peak pressure in the estimation of the end-systolic pressurevolume relationship. Circulation 1984;70:1057-65.

13. Tsakiris AG, von Bernuth G, Rastelli GC, Bourgeois MJ, Titus JL, Wood EH. Size and motion of the mitral valve annulus in anesthetized intact dogs. J Appl Physiol 1971;30:611-8.

14. van Rijk-Zwikker GL, Mast F, Schipperheyn JJ, Huysmans HA, Bruschke AVG. Comparison of rigid and flexible rings for annu- loplasty of the porcine mitral valve. Circulation 1990;82(Suppl): IV58-64.

15. Ormiston JA, Shah PM, Tei C, Wong M. Size and motion of the mitral valve annulus in man. I. A two-dimensional echocardiographic method and findings in normal subjects. Circulation 1981;64:113-20.

16. Levine RA, Handshumacher MD, Sanfilippo AJ, Hagege AA, Harrigan P, Marshall JE, et al. Three-dimensional echocardiographic reconstruction of the mitral valve, with implications for the diagnosis of mitral valve prolapse. Circulation 1989;80:589-98.

17. Komoda T, Hetzer R, Uyama C, Siniawski H, Maeta H, Rosendahl $\mathrm{UP}$, et al. Mitral annular function assessed by $3 \mathrm{D}$ imaging for mitral valve surgery. J Heart Valve Dis 1994;3:483-90.

18. Pai RG, Tanimoto M, Jintapakorn W, Azevedo J, Pandian NG, Shah PM. Volume-rendered three-dimensional dynamic anatomy of the mitral annulus using a transesophageal echocardiographic technique. J Heart Valve Dis 1995;4:623-27.

19. Komoda T, Hetzer R, Oellinger J, Siniawski H, Hofmeister J, Hubler M, et al. Mitral annular flexibility. J Card Surg 1997; 12:102-9.

20. van Rijk-Zwikker GL, Schipperheyn JJ, Huysmans HA, Bruschke AVG. Influence of mitral valve prosthesis or rigid mitral ring on left ventricular pump function: a study on exposed and isolated blood-perfused porcine hearts. Circulation 1989; 80(Suppl):I1-7.

21. Glasson JR, Komeda M, Daughters GT, Bolger AF, Karlsson MO, Foppiano LE, et al. Early systolic leaflet "loitering" during acute ischemic mitral regurgitation. J Thorac Cardiovasc Surg 1998;116:193-205.

\section{Bound volumes available to subscribers}

Bound volumes of The Journal of Thoracic and Cardiovascular Surgery are available to subscribers (only) for the 1999 issues from the Publisher, at a cost of $\$ 134.00$ for domestic, $\$ 165.85$ for Canadian, and $\$ 155.00$ for international subscribers for Vol 117 (January-June) and Vol 118 (July-December). Shipping charges are included. Each bound volume contains a subject and author index and all advertising is removed. Copies are shipped within 60 days after publication of the last issue of the volume. The binding is durable buckram with the Journal name, volume number, and year stamped in gold on the spine. Payment must accompany all orders. Contact Mosby, Inc, Subscription Services, 11830 Westline Industrial Drive, St Louis, MO 63146-3318, USA; phone 800-453-4351 or 314-453-4351.

Subscriptions must be in force to qualify. Bound volumes are not available in place of a regular Journal subscription. 